\title{
A Study on Career Choice Related to Decision Making by Student
}

\section{Neeraj Gautam}

Department of Humanities and Social Sciences, MNNIT, Allahabad, India

\section{Email address:}

rhu1651@mnnit.ac.in

\section{To cite this article:}

Neeraj Gautam. A Study on Career Choice Related to Decision Making by Student. International Journal of Vocational Education and Training Research. Vol. 3, No. 4, 2017, pp. 36-39. doi: 10.11648/j.ijvetr.20170304.12

Received: August 29, 2017; Accepted: September 20, 2017; Published: November 15, 2017

\begin{abstract}
In era of cut throat competition it' s a very crucial and change able to opt subjects or career as future, for those who are hail from rural areas and unable to access of any kind of E-medium of communication as well as not getting the right resource person to whom they take the suggestions or counseling that which specialization as subject they will study at school level and has futures cope also, on the contrary the urban student they have a very clear vision about the career choice Decision, because people from cities they are Electronic savvy in nature and within second get each and every information on the single screen, the parents from rural areas they don't afford Electronic Gazette that's why they fail to help in opting the correct stream so, this paper is basically to find out solution for the rural children and youngster so that they make their future bright by deciding the most aspiring and booming field as a career choice or which stream opt after high school and which course to pursue at undergraduate college.
\end{abstract}

Keywords: Cut-Throat Competition-Medium of Communication, Career Choice Decision, Electronic

\section{Introduction}

Career is an important aspect in life. An individual's decision of his or her decision regarding career is a life altering milestone which shapes up the future events that he or she will face. Choosing a career is thus an important event in the life of any individual. It is influenced by three factors, influence of parents, relatives and friends, which is the society around an individual, influence of the personal ambition and the influence by the innate capability and potential. It is important to analyze the effect of the various underlying factors behind the career decision making process so as to understand how the decision making process takes place and to ascertain the various dimensions and dynamics involved.

\subsection{Career}

The word "career" is defined as a person's course or progress through life or a significant portion of life. (Oxford English Dictionary) Career really is the primary force behind a person's life - his/her day-to-day activities are linked to it, in some way or the other. It is the interaction of work roles over a person's lifespan. People create career patterns as they make decision about education, work and family. (Handbook on Career Counselling, 2002) Since, it is a thing that will shape the whole life and make one remember for his/her choice of career, it becomes very important to choose the right one. Many a times, people generally use the words, "career", "job" and "occupation" as synonyms. But this is not so. Career - The sequence and variety of occupations which a person undertakes throughout lifetime. The progress and actions taken by a person throughout a lifetime, especially those related to that person's occupations. A career is often composed of the jobs held, titles earned and work accomplished over a long period of time, rather than just referring to one position.

\subsection{Career Choices}

With the industrialization of an agrarian economy and the effect of the external factor of globalization, there has been an increase in the number of jobs, not just in terms of number, but also in variety. A student thus is faced with a number of choices that he has to choose from. The Indian school curriculum laid by the Central Board of Secondary Education, after the Kothari Commission, mandates a student to choose the subject stream after high school. 
The four streams are

1. Science (Math's)

2. Science (Biology)

3. Commerce

The following give few of the numerous choices available.

1. Armed Forces

2. Architecture

3. Government Services

Career Choices under Science (Biology)

1. Medicine

2. Para-Medical

3. Botanist

4. Zoologist

5. Biotechnology

Career Choices under Commerce

1. Accountant

2. Economist

3. Management

4. Actuarial

Career Choices under Humanities

1. Sociologist

2. Social Work

3. Government Service

\subsection{Choice/Decision Making}

Everywhere, every time, we are faced with choices which we have to decide on. From choosing a dish from a menu card in a restaurant, to life-altering choices based on the career path. Decision making (decision from Latin decidere "to decide, determine," literally "to cut off," from de- "off" and caedere "to cut") can be regarded as the mental processes (cognitive process) resulting in the selection of a course of action among several alternative scenarios. Every decision making process produces a final choice. The output can be an action or an opinion of choice. (Wikipedia.com) The steps comprising the process of decision making are- (Pijanowski, 2009) Establishing community: creating and nurturing the relationships, norms, and procedures that will influce how problems are understood and communicated. This stage takes place prior to and during a moral dilemma.

a) Perception: recognizing that a problem exists.

b) Interpretation: identifying competing explanations for the problem, and evaluating the drivers behind those interpretations.

c) Judgment: sifting through various possible actions or responses and determining which is more justifiable.

d) Motivation:examining the competing commitments which may distract from a more moral course of action and then prioritizing and committing to moral values over other personal, institutional or social values.

e) Action: following through with action that supports the more justified decision. Integrity is supported by the ability to overcome distractions and obstacles, developing implementing skills, and ego strength.

f) Reflection

When we take a decision or make a choice, there are underlying factors, internal or external, that influence our action. In the field of career and its related choice making by a student, there may be the following factors influencing the choice making:

1. Parents

2. Social Under-Currents

3. Peer-Pressure

4. Teachers

5. Aspiration/Influence

6. Innate Potential and its Realization

The reason and motivation behind this study comes from the idea of the venture. As it is dealing with the career dynamics of the students, it is an imperative to conduct a research so as to understand the various perspectives and dynamics and process when it comes to career decision making of the students. The problems addressed by the venture are:

a) Absence of any educational consultancy affordable to middle-class.

b) Absence of any service enabling students to realize themselves, their aptitude, potential and areas of interest.

c) Absence of medium providing information regarding alternative careers.

The linking of a degree or a higher education to placement figures has quantified education, which essentially is qualitative. Comparison between figures thus is inevitable. A degree from a prestigious institute is the new upper "caste", which is most sought after by students and parents alike. In such circumstances, hardly anyone, especially parents, think of counselling and career guidance as a value proposition. The dream of getting the highest pay-package trumps down the rational decisions, like that of choosing a career which suits a person the most Cinemas is a mirror to the society. Of late, movies like Taare Zameen Par and 3 Idiots have emphasized the need to let go of the herd mentality and let a child pursue his/her dreams.

\section{Literature Review}

\subsection{The Theory of Work Adjustment (TWA)}

(Dawis, 2002, 2005; Dawis \& Lofquist,1984) is class of theory in career development that is anchored on the individual difference tradition of vocational behavior (Dawis, 1992) called person - environment correspondence theory, viewing career choice and development as continual processes of adjustment and accommodation in which: (a) the person $(\mathrm{P})$ looks for work organisations and environments(E) that would match his/her "requirements" in terms of needs, and (b) $\mathrm{E}$ in turn looks for individuals who have the capabilities to meeting the "requirements" of the organisation. The term satisfaction is used to indicate the degree that $\mathrm{P}$ is satisfied with $\mathrm{E}$, and satisfactoriness is used to denote the degree that $\mathrm{E}$ is satisfied with $\mathrm{P}$. To $\mathrm{P}$, the most central requirements to meet from $\mathrm{E}$ are his/her needs (or rein forcers), which could be further dissected into categories of psychological and physical needs that are termed values. To 
E, however, the most central requirements are abilities, which are operationalized as dimensions of skills that $\mathrm{P}$ possesses that are considered necessary in a given E. Overall, the degree of P's satisfaction and E's satisfactoriness would jointly predict P's tenure in that work environment. Career choice and development is thus conceptualized as a continual process or cycles of work adjustment initiated by dissatisfaction and dissatisfactoriness.

\subsection{Indigenisation of Career Theories for Relevance in the Indian Context}

The big five career theories are all developed in the USA but as evident from the review above, they have served to guides career guidance practice and research internationally. Even though the big five theories have been revised and updated in response to emerging research evidence and social changes, they are still conceptually and empirically anchored in the social and occupational contexts of the USA, and career guidance practitioners and researchers should be careful not to transport these theories to their own contexts without cultural adaptation and modifications (Leung, 1995). A review of the conceptual literature in career development suggested that very few career development theories have emerged from regions outside the USA. In order to advance the career guidance discipline in India, there should be more "indigenous" efforts to develop theories and practice that would meet the idiosyncratic needs in the country's diverse geographic, social, cultural and lingual regions. Indigenisation of career and guidance theory and practice should aim to identify the universals as well as the unique experience, constructs and practice that are specific to particular communities, classes and sections of society.

\section{Objective of the Study}

a) To ascertain the social background of the respondents.

b) To explore and analyze, how a student makes a decision regarding which career to choose, which stream to take after high school and which course to pursue at undergraduate college.

c) To analyze the underlying factors influencing such decision.

d) To explore the students' perspective regarding their decision and the influencing factors.

e) To ascertain whether the students are contented by the careers they have chosen.

\section{Research Methodology}

Quantitative Research methodology was selected for this study. Self created Questionnaire was used for this purpose

\subsection{Methods of Sampling}

Stratified-Random Sampling method was applied for sampling. 15 to 19 years old students studying in higher secondary, senior secondary and graduation were targeted as sample for this study.

\subsection{Sampling Frame}

The total size of sample was 72 . In which 15 students were about to pass from high school and were going through the stressful and confusing state of choosing their career after few months. 57 students were in $11^{\text {th }}$ or $12^{\text {th }}$ and already took the decision for their career. Total number of boys in the sample was 37 and girls were 35 . In the 57 higher secondary and graduate students 33 students opted for science, 19 students opted for commerce and 5 students opted for humanities. In the 15 students who were going to choose their specific subjects, 10 wanted to take science, 3 wanted to take commerce and 2 wanted to take humanities.

\subsection{Tool of Data Collection}

Self formed questionnaire and informal talk with students, teachers and parents were tools of data collection. Questionnaire was formed after studying huge number of books and research studies on career choices, news and surveys about student's satisfaction, dissatisfaction and pressure for doing well in the exams and job.

\subsection{Method of Data Collection}

Research was done in Azamgarh village Most of the participants were at least higher secondary passed and went through the decision making process for their career.15 of them were in higher secondary school and going through the decision making process. Questionnaire contained 22 Number of questions, in which all the relevant questions for researcher's objectives in this study were asked. Participants took 15-25 minutes to fill the farm which differed by person to person.

\section{Findings}

In the process of the survey to collect the data, the questionnaire was sent online to about 150 prospective students that fit into the criteria set in the research study. But only 72 of the whole filled the questionnaire and sent us back. This variable was included in the study to analyze any patterns of choice making between the two sexes and conclude if there are any generalities to make or conclusions to be drawn.

Table 1. Sex

\begin{tabular}{lllll}
\hline & Frequency & Percent & $\begin{array}{l}\text { Valid } \\
\text { Percent }\end{array}$ & $\begin{array}{l}\text { Cumulative } \\
\text { Percent }\end{array}$ \\
\hline Male & 37 & 51.4 & 51.4 & 51.4 \\
Valid Female & 35 & 48.6 & 48.6 & 100.0 \\
Total & 72 & 100.0 & 100.0 & \\
\hline
\end{tabular}

As depicted in the table, out of 72, 37 were female and 35 were male respondents. This means that about $51.4 \%$ were male and $48.6 \%$ of the total was female. Hence it can be said from above that the study was almost at parity between the two sexes and thus ruled out the factor of any gender bias or 
neglect that might have happened. This may indicate that more number of boys choose Science while more number of girls choose Commerce.

Table 2. Age of Respondents.

\begin{tabular}{lllll}
\hline & Frequency & Percent & $\begin{array}{l}\text { Valid } \\
\text { Percent }\end{array}$ & $\begin{array}{l}\text { Cumulative } \\
\text { Percent }\end{array}$ \\
\hline $13-15$ & 15 & 20.8 & 20.8 & 20.8 \\
$15-18$ & 51 & 70.8 & 70.8 & 91.7 \\
Valid & & & & \\
$18-21$ & 6 & 8.3 & 8.3 & 100.0 \\
Total & 72 & 100.0 & 100.0 & \\
\hline
\end{tabular}

As depicted in the table 2 respondents out of the 72 were in the age group of 13 to 15 years, constituting $20.8 \%$ percentage of the total respondents. 51 were under the age group of 15 to 18 , making them $70.8 \%$ of the total and 6 respondents were of the age group 18 to 21 , making them $8.3 \%$ of the total respondents.

Table 3. Subject

\begin{tabular}{lllll}
\hline & Frequency & Percent & $\begin{array}{l}\text { Valid } \\
\text { Percent }\end{array}$ & $\begin{array}{l}\text { Cumulative } \\
\text { Percent }\end{array}$ \\
\hline Science & 43 & 59.7 & 59.7 & 59.7 \\
Commerce & 22 & 30.6 & 30.6 & 90.3 \\
Valid & & 9.7 & 9.7 & 100.0 \\
Arts & 7 & 100.0 & 100.0 & \\
Total & 72 & &
\end{tabular}

As depicted in the table 3, 60 respondents were still in school, so they left the question blank and didn't respond. 4 respondents were pursuing BA, 3 were doing B.Com, 1 was pursuing B.Sc and 4 were pursuing B.Tech.

Table 4. Motivation-Money.

\begin{tabular}{lllll}
\hline & Frequency & Percent & $\begin{array}{l}\text { Valid } \\
\text { Percent }\end{array}$ & $\begin{array}{l}\text { Cumulative } \\
\text { Percent }\end{array}$ \\
\hline No & 15 & 20.8 & 20.8 & 20.8 \\
Valid Yes & 57 & 79.2 & 79.2 & 100.0 \\
Total & 72 & 100.0 & 100.0 & \\
\hline
\end{tabular}

57 respondents said "Yes", making them $79.2 \%$ of the total respondents, while 15 respondents said "No", making them $20.8 \%$ of the total respondents

\section{Conclusion}

This study was framed with the assumption that dissatisfaction with the course, career and work load is not a sudden concern for anyone, there should be something hidden from the beginning which leads them towards a stressful and uninteresting readings and dissatisfying job and work profile. Because of this stress and dissatisfaction many people have to face mild or severe depression, distress and sometime they prefer ending their life over this continuous stress and confusion about their future. From the cumulative result of this study it is clear that current way of choosing career and taking decision is not that beneficial, productive and satisfactory for students. On the basis of these findings some basic changes in the process of making choice and taking decision can be proposed, as career counseling by the professionals which could help the student to choose a subject which is suitable for him and for which he is suitable.

\section{References}

[1] Dick, T. P., \& Rallis, S. F. (2012). Factors and influences on high school.

[2] Friedman, N. L., Friedman, S. S., \& Friedman, L. (2012). as Sociology Occupational Career and Employment counseling : Patterns \& Possibilities 18(3), 284-295.

[3] Frith, G. H., Armstrong, S., Frith, G. H., \& Armstrong, S. (2012). Career Preparation for Behavior Disorder Adolescent: Involving the Family, 33(1), 143-147

[4] Goldin, C. (2004). The Long Road to the Fast Track: Career and Family. The ANNALS of the American Academy of Political and Social Science, 596(1), 20-35. doi:10.1177/0002716204267959

[5] Hall, D. T., \& Chandler, D. E. (2005). Psychological success: When the career is a calling. Journal of Organizational Behavior, 26(2), 155-176. doi:10.1002/job.301

[6] Jacobs, J. A., Karen, D., Mc clelland, K., Jacobs, J. A., Karen, D., \&Mcclelland, K. (2012). The Dynamics of Young Mens Career Aspirations 1, 6(4), 609-639.

[7] Klapwijk, R., \& Rommes, E. (2009). Career orientation of secondary school students $(\mathrm{m} / \mathrm{f})$.

[8] Leung, S. A. (2008). The big five career theories, (d), 115132Publishing (2012a). Statusand Career Decision: An Analysis of the time dimensions 13(4)496507.

[9] Publishing (2012) career: The Subjective Approach 11 (1)32-49.

[10] Reitz J. G (2012) Undergraduate aspirants and career choice: Effects of colleges electivity 48(3), 308-323

[11] Adam, A. F. and Fayolle, A. (2016), "Canimplement ationin tention help to bridge the intention-behavior gap in the entrepreneurial process? An experimental approach", International Journal of Entrepreneurship and Innovation, Vol.17No.2, pp.80-88.

[12] Adam, A. F. and Fayolle, A. (2016), "Can implementation intention help to bridge the intention-behaviour gap in the entrepreneurial process? An experimental approach", International Journal of Entrepreneurship and Innovation, Vol. 17 No. 2, pp. 80-88.

[13] Arregle, J. L., Batjargal, B., Hitt, M. A., Webb, J. W., Miller, T. and Tsui, A. S. (2015) "Family ties in entrepreneurs social networks and new venture growth", Entrepreneurship Theory and Practice Vol. 39 No. 2, pp. 313-344.

[14] Fayolle, A. and Gailly, B. (2015), "The impact of entrepreneurship education on entrepreneurial attitudes and intention: hysteresis and persistence", Journal of Small Business Management, Vol. 53 No.1, pp. 75-93.

[15] Zapkau, F. B., Schwens, C. and Kabst, R. (2017), "The role of prior entrepreneurial exposure in the entrepreneurial process: a review and future research implications", Journal of Small Business Management, Vol. 55 No. 1, pp. 56-86. 